\title{
Impact of a methadone maintenance program on an Aboriginal community: a qualitative study
}

\author{
Michel Landry MD, Nadia Veilleux MD, Julie-Eve Arseneault MD, Saneea Abboud MD, \\ André Barrieau MD, Mathieu Bélanger PhD
}

\section{Abstract}

Background: Methadone maintenance treatment programs implemented in Aboriginal communities have proven to be beneficial for the control of opioid addiction and its associated consequences, but the perceptions and opinions of different community members about these programs remain elusive. The goal of this study was to determine the perceptions of members of a First Nation community in New Brunswick, Canada, on the implementation of a methadone maintenance treatment program and its effects on the community.

Methods: We conducted a qualitative study using semistructured focus group discussions with 3 distinct groups composed of health care professionals and influential community members, patients in the methadone maintenance treatment program and community members at large. Thematic analysis of discussion transcripts was performed.

Results: A total of 22 partipants were included in the 3 focus groups. All groups of participants expressed that patients in the program are stigmatized and marginalized. Discussions also revealed widespread misconceptions about the program. Participants associated the program with improvements in community-level outcomes and in parenting abilities of patients, but also with difficulties preserving family unity.

Interpretation: Despite being culturally adapted to the community, elements surrounding the methadone maintenance treatment program in this First Nation community appear to be misunderstood and stigmatized. It may be beneficial to provide community education on these programs to assure community buy-in for the successful implementation of harm reduction programs in Aboriginal communities.

\begin{abstract}
Tlicit drug use and dependence continue to plague populations worldwide and contribute to the global burden of disease. ${ }^{1}$ Further contributing to the world's drug problem is the ever-growing epidemic of nonmedical usage of prescription drugs. ${ }^{2}$ Among illicit and prescription drugs, opioids are responsible for the highest rates of morbidity and mortality related to problematic drug use. ${ }^{3}$ In Canada, the prevalence of illicit opioid (heroin) use is estimated at $0.9 \%,{ }^{4}$ and the misuse of prescription opioids was reported in $5.2 \%$ of the general population. ${ }^{5}$ Patients with opioid dependence are at an increased risk of infectious diseases, including viral hepatitis ${ }^{6}$ and HIV. ${ }^{7}$ Premature death in these patients is multifactorial, but HIV/AIDS-related complications and drug overdose represent the major causes of death in people who inject drugs. ${ }^{89}$ Illicit opioid use also has societal consequences, with individuals who are engaged in risky use of opioids being affected by poverty, homelessness and criminality more frequently than the general population. ${ }^{10}$ Opioid addiction has been recognized as a chronic relapsing condition that can be controlled through pharmacotherapy maintenance programs. The most predominant form of opioid
\end{abstract}

pharmacotherapy is the administration of oral methadone through methadone maintenance treatment programs. ${ }^{11}$ These programs have proven benefits at both the individual and societal levels, including reductions in use of injection drugs, acquisition and transmission of viral hepatitis and HIV, death, crime rates, and improvements in participants' overall quality of life. ${ }^{11,12}$

In Canada, ${ }^{13}$ the United States ${ }^{14}$ and Australia, ${ }^{15}$ rates of opioid dependence tend to be higher in Aboriginal than in non-Aboriginal communities, as are the rates of associated harms and death. ${ }^{16}$ However, the beneficial effects of methadone programs are similar among both Aboriginal and

Competing interests: None declared.

This article has been peer reviewed.

Correspondence to: Mathieu Bélanger, mathieu.f.belanger@ usherbrooke.ca

CMAJ Open 2016. DOI:10.9778/cmajo.20150076 
non-Aboriginal participants. ${ }^{17-19}$ A report from the Health Council of Canada highlighted the importance of considering and respecting culture in Aboriginal health care to offer "culturally competent care" in "culturally safe environments." Although this applied to harm reduction strategies, it was suggested that the implementation of methadone maintenance treatment programs within Aboriginal communities can be accompanied by apprehension and distrust. ${ }^{21}$ Thus, although individual-level benefits of methadone programs have been established, knowledge on the perceptions and opinions of Aboriginal communities on these programs remains elusive.

The First Nation reserve of Elsipogtog (population 3272) is located in southeastern New Brunswick, Canada. The Elsipogtog methadone maintenance treatment program was started at the Elsipogtog Health \& Wellness Centre in 2007 to help counter the community's high rates of substance abuse and its related consequences. The program's mission is true to First Nation cultural beliefs and provides care according to the native medicine wheel. Most of the program's staff are from the Elsipogtog community and provide services in Mi'kmaq. They include a family physician, a nurse practitioner, a registered nurse, an alcohol-drug counsellor and a psychologist, as well as a traditional elder and a medical receptionist who provide ancillary services.

To improve our understanding of how methadone maintenance treatment programs may be received in Aboriginal communities, the main objective of this qualitative study was to determine the perceptions of members of the Elsipogtog First Nation on the Elsipogtog treatment program and the impact of its implementation on the community.

\section{Methods}

\section{Study design}

We conducted a descriptive qualitative study that involved 3 distinct semistructured focus group discussions. This approach was selected for its ability to rapidly reveal a broad range of ideas on a specific topic. ${ }^{22}$ Focus groups also facilitate social interactions, which can help identify how a group represents issues with the help of facilitators who can also stimulate participants to balance others' statements with different points of view, when applicable. ${ }^{22,23}$ This study was approved by the Elsipogtog Health and Wellness Centre, the Elsipogtog Band Council and the Vitalite Health Network (local regional health authority) Research Ethics Board.

\section{Study participants and setting}

Participants were purposely selected to represent 3 distinct groups of interest within the Elsipogtog community: health and social professionals and other influential members of the community involved in the delivery or management of the methadone maintenance treatment program (professional group); patients in the program (patient group); and other Elsipogtog community members who had no association with the program (community group). Participants who self-identified as belonging to 1 of these 3 groups were eligible for inclusion. One focus group discussion was held separately with each group. The goal of creating 3 mutually exclusive focus groups was to make participants as comfortable as possible with sharing their thoughts. In addition, we aimed to avoid contamination of one group's experiences over the experiences of another group, so that perceptions and interpretations based on different perspectives could emerge.

Different recruitment strategies were deployed for the different groups of participants, including direct contact via telephone by the health centre's nurse for the professionals group, letters for the patients group and poster advertisements for the community group. The focus group discussions took place in 2012 at the community's healing lodge, which is located within the health centre.

Collecting data 5 years after the implementation of the treatment program was considered sufficient for it to have been deployed completely while also enabling people to accurately recall the period preceding its implementation. Three researchers (Julie-Eve Arseneault, Saneea Abboud, Nadia Veilleux) and a Mi'kmaq translator were present during the discussions. Although participants were offered a light lunch, they were not compensated for their participation.

\section{Data collection}

All discussions began with an explanation of the purpose and structure of the meeting, with an encouragement for all participants to take part in the discussion and with reiteration of the importance of respecting the confidentiality of participants and statements expressed during the discussions. A semistructured discussion guide was developed by reviewing relevant literature and by drawing on the researchers' experience. Specifically, the 6 main questions were the same for each group and targeted attitudes regarding perceived positive and negative effects of the methadone maintenance treatment program on the community, families, spirituality, crime, employment and cultural values. The sessions lasted about 2 hours and were audio-recorded. The researchers took field notes that were used as a starting point for analyses.

\section{Data analysis}

The discussions were anonymized and transcribed verbatim. Three research team members (Nadia Veilleux, Saneea Abboud, Julie-Eve Arseneault) independently conducted a thematic analysis of the data. Thereafter, researchers discussed the themes identified in the analysis and agreed on common themes, which they used to code the discussions. The list of derived themes was then further refined by grouping those that were strongly interconnected. During this stage, particular attention was paid to identifying similarities and differences between the 3 groups. In the final stage, 2 other researchers (André Barrieau, Mathieu Bélanger) reviewed the final coded data to ensure the higher-order themes were representative of the raw data. Their assessment was in agreement with the coding scheme, which enhances the credibility and trustworthiness of the findings reported in this study. Focus group participants reviewed and provided feedback on the findings. 


\section{Results}

The study included a total of 22 participants. The professionals group consisted of 12 participants, including representatives from child and family services, a welfare program, a justice program, the Royal Canadian Mounted Police, a local drug and alcohol rehabilitation program, community elders, social workers, nurses from the methadone maintenance treatment program and the band council. The patient group included 6 participants. Finally, the community group included 4 participants. Ten of the 12 members of the professionals group, and all members of the patient and community groups, were Aboriginal. Themes that emerged from the analysis are described and organized according to the topics that were addressed during the focus group discussion (Table 1). Although similar themes emerged among participants from the different groups, there were marked between-group differences in terms of perceptions and attitudes with regard to many of the themes. Examples of statements for all identified themes are included in Table 1.

\section{Stigma and marginalization of patients in the methadone maintenance treatment program}

All 3 groups agreed that the stigmatization of patients in the program is prevalent within the community. Patients fall victim to many negative stereotypes. For example, participants from all groups felt that patients in the program were often perceived as being "always high," thieves and untrustworthy. Because of this stigmatization, patient participants revealed being subjected to discriminatory treatment in different community settings. Participants from the professionals and community groups agreed, stating that patients from the program were not welcome in sweat lodges. Although the general sentiment was clearly that patients did not belong and were often excluded from spiritual practices, this feeling was nuanced with community and professional participants saying that patients might be welcomed "depending on the situation." It was not clear what such situations may be, given participants from the same 2 groups mentioned that methadone and spirituality "don't mix" and that if you take a drug, such as methadone, "the spirit leaves the body and spirituality is, therefore, not possible."

Patient participants felt that discrimination against them extended beyond spiritual settings, reporting that employers discriminate against people on the methadone maintenance treatment program and that if they do get a job, they are treated differently. Community group members nevertheless nuanced this by stating that the community's $80 \%$ unemployment rate makes it difficult to find work for anyone, not only patients in the treatment program.

Table 1: Summary of identified themes

Themes

Example statements

Stigma and marginalization "They are always high." (Community member)

"Ceremony requires your pure self (...) It comes down to self-respect, respect the teaching of the lodge." (Community member)

"Like going to the mall, too, security guards at the camera seem to watch the methadone users at the mall... scared they're going to steal. It's like l've got some money here. I hate when those workers are folding clothes and watching you..." (Patient)

Misinformation Assuming that methadone maintenance is simply "substituting one drug for another drug" (community member)

"When I first heard about it, I thought everybody would be walking around high all the time. I didn't understand how you'd substitute one drug for another drug (...) eventually I just got on the program. I still didn't understand the concept of replacing a drug with another drug. Then I got on the methadone and life started getting better. My idea of methadone changed in the last couple of years from a negative to a positive." (Patient)

Sense of improvement "Before methadone you'd walk around and saw needles everywhere and stuff like that. You don't see that anymore. I think the 100 people on methadone, it's that less needles going around. If one of those 100 people had diseases, that's less diseases going around. There's so many benefits, really, people don't realize how much it's changed... It's like they forget. They used to see us walking around like bones, people forget that. Did they think we were all right or something? I don't know why people are against methadone. I was before. I guess I didn't know, that's why." (Patient)

"Even the pawn shop closed down." (Community member)

"Before, your brother was stealing from you, your PlayStation, your games, your computer, even myself, I was stealing, shoplifting..." (Patient)

Effect on parenting

"For methadone patients, at least their kids will have food... They'll have an Easter and a Christmas and their kids' stuff won't be pawned the next day." (Patient)

"Young girls are getting pregnant to get on the program. Babies born from methadone, we have to take responsibility, because they were encouraged to get into the program..." (Professionals participant)

Family division

"My mom is on my side. I have two other sisters on methadone too, but my brother is so high class, he doesn't understand. It pisses me off... he'll say remarks about it." (Patient) 


\section{Misinformation and lack of information on the methadone maintenance treatment program}

Most participants in the community group seemed to disapprove of treatment program, often assuming that it simply consists of "substituting one drug for another" and that patients continue to abuse opioids. It became clear during these discussions that participants from all groups, including the patient group, were misinformed about what methadone was and lacked information on how the program was structured. Community group members were surprised to learn that all patients in the program underwent urine drug testing, which showed that their perception of patients in the program continuing to consume drugs while on the program was false. Participants in the professional and community groups also felt that the program should include more spiritual aspects and have a more holistic approach, not knowing that these are already aspects of the program in Elsipogtog. Nevertheless, other participants from the same 2 groups felt that more information should be provided to patients about alternatives to methadone maintenance, such as abstinence-based programs.

\section{Sense of general improvement}

Some participants from the professionals group and all participants from the patients and community groups described great progress in the cleanliness and safety of the community since the start of the program. Participants from all 3 groups noted a reduction in burglary and vandalism in the community. However, all groups agreed that the introduction of the treatment program had not changed the incidence of violent crimes. Participants in the professionals and community groups attributed this lack of change to the notion that these types of crimes were more frequently associated with alcohol dependence and not necessarily narcotics.

\section{Effect on parenting skills}

All groups agreed that the treatment program generally helped improve the parenting abilities of patients with children. Because the money of patients was no longer going toward the acquisition of drugs, participants from the professionals and patients groups felt that participation in the program allowed patients to better care for their children by being able to provide for their basic needs, such as clothing and food. However, patient group participants stated that it was not all positive, given that an adverse effect of their participation in the program was they were drowsier and more absent as parents, suggesting that although they were now better providers for their families, their overall availability to their children was still compromised. There were also concerns from the professionals and community groups that implementation of the program may have led to the creation of a new problem, which they referred to as the creation of "methadone babies." As they described it, women with opioid dependency might decide to get pregnant strategically as a means to advance their priority on the list of admission to the program.

\section{Integrity of the family unit}

All 3 groups suggested that the program led to difficulties preserving family unity, with families often being divided by dif- fering feelings about the program. These opposing views within families sometimes led to hostility and conflicts between family members.

\section{Interpretation}

Discussions from all 3 focus groups in this study showed a general negativity surrounding the Elsipogtog methadone maintenance treatment program. This finding is consistent with reports describing how abstinence-based therapy is the approach favoured by many members of Aboriginal communities for the treatment of addiction, although harm reduction approaches are often condoned..$^{24}$ Our data suggest that much of this negativity is based on a lack of information about methadone as a medication, about medication-assisted treatment and about the specifics of the program. For participants from the professionals and community group, the focus group discussions resulted in them acquiring more information about the functioning of the program, which resulted in the recognition of a need for more information regarding methadone and pharmacotherapy for the treatment of opioid addiction. The importance of community education efforts was highlighted in a study investigating barriers and opportunities in implementing harm reduction programs in First Nation communities in British Columbia. ${ }^{25}$ Group discussions held for that study also emphasized "the need for community buy-in for all aspects of harm reduction." Together, these results suggest that implementing a methadone maintenance treatment program within an Aboriginal community should be accompanied by a strategy for educating community members on the objectives and general methods of the program. Previous research shows that educating community members helps develop acceptance of culturally respectful health care delivery. ${ }^{26}$

All 3 groups agreed that patients in the program were subject to stigmatization. Participants from the patient group suggested that negative stereotypes associated with methadone patients led to them being subjected to discriminatory behaviour by other members of the community. Stigma and discrimination are recurring themes that have been reported by other authors. ${ }^{25,27}$ Both contribute substantially to the social marginalization of patients in methadone treatment programs, a phenomenon that was perceived by participants in all study groups. Misconceptions or misinformation concerning methadone was also suggested as a driver for excluding patients from different community settings by participants in the professionals and community groups. Some of these misconceptions seemed to stem from deeply rooted cultural and spiritual beliefs that led to the exclusion of patients from traditional Aboriginal rituals, such as the sweat lodge. The concept that methadone interferes with one's ability to experience spirituality was reported to be a common belief among Aboriginal people..$^{28}$

Participants from all groups perceived both positive and negative community-level effects of the program. At the family level, study participants recognized that patients who were parents were now better at providing care for their families as a result of their participation in the program. In contrast, participants from all groups suggested that the program compromised family unity because of the conflicting views of family 
members on methadone treatment. In addition, participants reported that since the implementation of the program, there was reduced crime in the community.

\section{Strengths and limitations}

We recruited 3 distinct groups of participants, each providing unique insight into the perceived effects of implementing a methadone maintenance treatment program. In addition, we included a member-checking step to complete the data interpretation process.

Interpretation of our results must be done while recognizing certain limitations. This study was conducted in only 1 rural Mi'kmaq community, and the results may not be representative of people from other First Nation communities in both rural and urban settings. In addition, the personal experiences of participants with the treatment program may have influenced their responses. Data were collected during group sessions, and participants may have been more comfortable and shared more information in 1-on-1 interviews. Because the 22 participants constituted 3 distinct groups, it was not expected to reach data saturation during the thematic analysis. Finally, participants in this study self-selected to take part, suggesting that the sample may not be representative of the community.

\section{Conclusion}

In this study, 3 distinct groups of people from an Aboriginal community perceived that the implementation of a methadone maintenance treatment program was associated with considerable improvements in general cleanliness and safety of the community. However, this positive effect was overshadowed by negative perceptions that were largely based on misinformation about the program. These results underline the importance of considering community-related outcomes when evaluating these or other health care programs implemented in First Nation communities. Implementation of methadone maintenance treatment programs in Aboriginal communities should be accompanied by community-level education to obtain appropriate community buy-in and facilitate the delivery of culturally respectful services.

\section{References}

1. Degenhardt L, Whiteford HA, Ferrari AJ, et al. Global burden of disease attributable to illicit drug use and dependence: findings from the Global Burden of Disease Study 2010. Lancet 2013;382:1564-74.

2. Fischer B, Argento E. Prescription opioid related misuse, harms, diversion and interventions in Canada: a review. Pain Physician 2012;15(Suppl):ES191-203.

3. World drug report 2014. United Nations publication, Sales No. E.14.XI.7. New York: United Nations Office on Drugs and Crime (UNODC); 2014.

4. Adlaf E, Begin P, Sawka E. Canadian Addiction Survey (CAS): a national survey of Canadians' use of alcohol and other drugs: prevalence of use and related harms. Ottawa: Canadian Centre on Substance Abuse (CCSA); 2005.

5. Canadian Alcohol and Drug Use Monitoring Survey. Ottawa: Health Canada; 2012. Available: www.hc-sc.gc.ca/hc-ps/drugs-drogues/stat/2012/tables -tableaux-eng.php\#t3 (accessed 2014 Nov. 17).

6. Nelson PK, Mathers BM, Cowie B, et al. Global epidemiology of hepatitis B and hepatitis $\mathrm{C}$ in people who inject drugs: results of systematic reviews. Lancet 2011;378:571-83

7. Mathers BM, Degenhardt L, Phillips B, et al. Global epidemiology of injecting drug use and HIV among people who inject drugs: a systematic review. Lancet 2008;372:1733-45.

8. Mathers BM, Degenhardt L, Bucello C, et al. Mortality among people who inject drugs: a systematic review and meta-analysis. Bull World Health Organ 2013;91:102-23
9. Degenhardt L, Bucello C, Mathers B, et al. Mortality among regular or dependent users of heroin and other opioids: a systematic review and metaanalysis of cohort studies. Addiction 2011;106:32-51.

10. Fischer B, Rehm J, Brissette S, et al. Illicit opioid use in Canada: comparing social, health, and drug use characteristics of untreated users in five cities (OPICAN study). 7 Urban Health 2005;82:250-66.

11. Haasen $C$, van den Brink W. Innovations in agonist maintenance treatment of opioid-dependent patients. Curr Opin Psychiatry 2006;19:631-6.

12. Feelemyer JP, Des Jarlais DC, Arasteh K, et al. Changes in quality of life (WHOQOL-BREF) and addiction severity index (ASI) among participants in opioid substitution treatment (OST) in low and middle income countries: an international systematic review. Drug Alcohol Depend 2014;134:251-8.

13. First Nations Regional Longitudinal Survey (RHS) 2002/03: results for adults, youth and children living in First Nations communities. Ottawa: First Nations Centre; 2007.

14. Whitesell NR, Beals J, Crow CB, et al. Epidemiology and etiology of substance use among American Indians and Alaska Natives: risk, protection, and implications for prevention. Am 7 Drug Alcohol Abuse 2012;38:376-82.

15. Haber PS, Day CA. Overview of substance use and treatment from Australia. Subst Abus 2014:35:304-8.

16. Milloy MJ, Wood E, Reading C, et al. Elevated overdose mortality rates among First Nations individuals in a Canadian setting: a population-based analysis. Addiction 2010;105:1962-70.

17. Black A, Khan S, Brown R, et al. An evaluation of opioid replacement pharmacotherapy in an urban Aboriginal Health Service. Aust N Z 7 Public Health 2007;31:428-32.

18. Oviedo-Joekes E, Guh D, Marsh DC, et al. Characteristics and response to treatment among Aboriginal people receiving heroin-assisted treatment. Can 7 Public Health 2010;101:210-2.

19. Wood E, Montaner JS, Li K, et al. Rate of methadone use among Aboriginal opioid injection drug users. CMA7 2007;177:37-40.

20. Empathy, dignity, and respect: creating cultural safety for Aboriginal people in urban bealth care. Toronto: Health Council of Canada; 2012

21. Williams N, Nasir R, Smither G, et al. Providing opioid substitution treatment to Indigenous heroin users within a community health service setting in Adelaide. Drug Alcobol Rev 2006;25:227-32.

22. Grbich C. Qualitative research in health: an introduction. London (UK): SAGE Publications; 1999.

23. Flick U. An introduction to qualitative research. 4th ed. London (UK): SAGE Publications; 2009.

24. van der Sterren AE, Anderson IP, Thorpe LG. 'Individual' harms, Community 'harms': reconciling Indigenous values with drug harm minimisation policy. Drug Alcohol Rev 2006;25:219-25.

25. Wardman D, Quantz D. Harm reduction services for British Columbia's First Nation population: a qualitative inquiry into opportunities and barriers for injection drug users. Harm Reduct 7 2006;3:30.

26. Petrucka $\mathrm{P}$, Bassendowski S, Bourassa C. Seeking paths to culturally competent health care: lessons from two Saskatchewan Aboriginal communities. Can $\mathcal{F}$ Nurs Res 2007;39:166-82.

27. Smye V, Browne AJ, Varcoe C, et al. Harm reduction, methadone maintenance treatment and the root causes of health and social inequities: An intersectional lens in the Canadian context. Harm Reduct 7 2011;8:17.

28. Teasdale KE, Conigrave KM, Kiel KA, et al. Improving services for prevention and treatment of substance misuse for Aboriginal communities in a Sydney Area Health Service. Drug Alcobol Rev 2008;27:152-9.

Affiliations: Department of Family Medicine (Landry, Bélanger, Veilleux, Arseneault, Abboud, Barrieau), Université de Sherbrooke, Sherbrooke, Que.; Centre de formation médicale du Nouveau-Brunswick (Bélanger, Veilleux, Arseneault, Landry, Abboud, Barrieau), Université de Moncton, Moncton, NB

Contributors: Michel Landry conceived the original objective of the study. The study was designed by Nadia Veilleux, Julie-Eve Arseneault, Saneea Abboud and Mathieu Bélanger. Nadia Veilleux, Julie-Eve Arseneault and Saneea Abboud led the recruitment, data acquisition and data analysis processes. All of the authors contributed to the analysis and interpretation of the data and the writing of the manuscript. All of the authors reviewed the manuscript critically for important intellectual content, approved the final version to be published and agreed to act as guarantors of the work.

Acknowledgements: The authors thank Brigitte Sonier Ferguson for her assistance in the conception and revisions of this manuscript.

Supplemental information: For reviewer comments and the original submission of this manuscript, please see www.cmajopen.ca/content/4/3/ E431/suppl/DC1 